\title{
Adaptive Phase-Shifted PWM for Multilevel Cascaded H-bridge Converters with Large Number of Power Cells
}

\author{
Abraham Marquez $^{1}$, Jose I. Leon ${ }^{1}$, Sergio Vazquez ${ }^{1}$, Leopoldo G. Franquelo ${ }^{1}$ and Samir Kouro ${ }^{2}$ \\ ${ }^{1}$ Department of Electronics Engineering, \\ University of Seville \\ Seville, Spain, \\ jileon@gte.esi.us.es \\ ${ }^{2}$ Department of Electronics Engineering, \\ Universidad Tecnica Federico Santa Maria \\ Valparaiso, Chile, \\ samir.kouro@ieee.org
}

\begin{abstract}
Cascaded H-bridge multilevel converters are usually applied for high-power systems with independent dc sources. It can be used as PV inverter or to operate independent battery stacks. In these cases, as each dc source can be working at different operational points, conventional modulators lead to high distorted output waveforms degrading the converter performance. In this paper, a modulation method as a modified version of conventional phase-shifted PWM is presented when the CHB converter has a large number of power cells. This method is an extension of a previous technique only suitable for CHB converters with three power cells per phase. Simulation results show the good performance of the proposal with higher number of cells.
\end{abstract}

\section{INTRODUCTION}

Multilevel converters have become a mature technology in the last decades for applications such as fans, pumps, motor drives, flexible ac transmission systems (FACTS), high-voltage dc systems or renewable energy sources integration, among others. They present advantages for medium-voltage applications using serial connection of power devices to achieve high nominal power levels with high performance output waveforms [1]-[8].

One of the most conventional multilevel converter topologies is the cascaded H-bridge power converter (CHB) which is formed by the serial connection of power cells (usually full bridges). It has been successfully applied as motor drive or FACTS presenting high modularity and fault tolerant capability [9], [10]. In Fig. 1, a six-cell CHB converter is represented.

In this paper, the $\mathrm{CHB}$ converter is considered where different dc sources are connected to the dc side (independent PV arrays or batteries). As addressed in [11], [12], the good performance of the converter is degraded if the dc sources are not equal leading to high distortion at twice the carrier frequency if a conventional phase-shifted PWM (PS-PWM) modulation is used. In [12], the problem is mitigated for CHB converters with three cells but no solution is addressed if the number of cells is higher. The aim of this paper is to present possible solutions if the number of cells of the CHB is more than three.

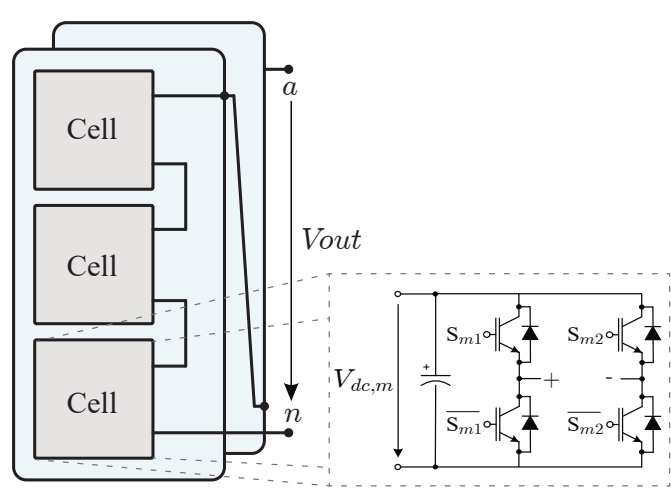

Fig. 1: Six-cell cascaded H-bridge power converter

\section{Conventional Phase-Shifted PWM for CHB CONVERTERS}

Nowadays many researchers are focused on developing new efficient modulation strategies for multilevel converters [13] [16]. There are a large number of modulation methods but, as a rule, the multi-level $\mathrm{CHB}$ converter is operated using a traditional PS-PWM. This modulation technique is based on the generation of the same reference voltage for all power cells that compose the power converter. Each H-bridge is operated using an independent unipolar PWM modulation. According to this fact, the phase displacement between two consecutive H-bridge is given by $180^{\circ} / M$ where $M$ is the total number of H-bridges of the power converter. As a result, the output voltage waveform of all the power cells very similar with a offset in time [4]. As an example, the PS-PWM method is represented in Fig. 2 for three-cell CHB converter.

A CHB converter operated by PS-PWM technique presents the following advantages:

- Balanced power distribution in the H-bridges

- Equalization of power losses between the H-bridges

- Multiplicative effect of the total switching frequency. It is located at $M$ times the frequency of an unipolar PWM technique (which is two times the triangular carrier frequency $f_{\text {pwm }}$ ) 

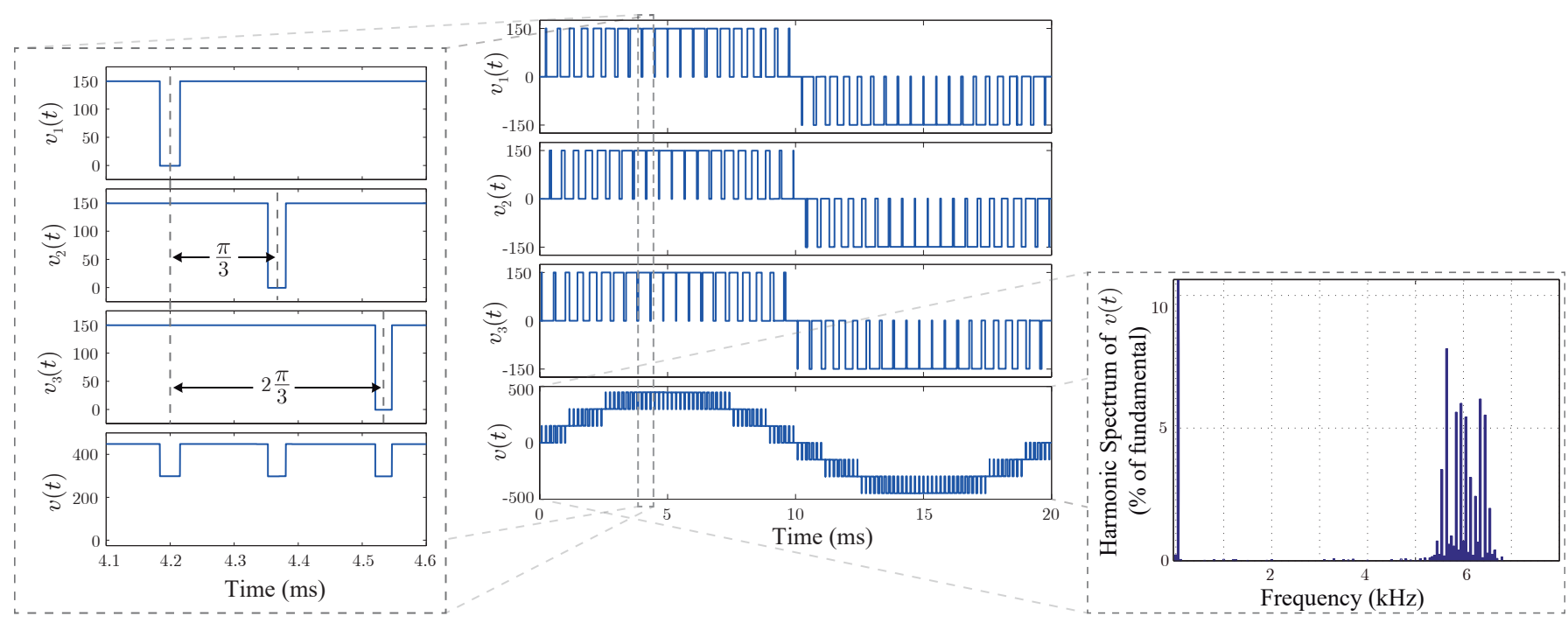

Fig. 2: Output voltages of power cells in a three-cell CHB power converter and total output voltage using conventional PS-PWM. The carrier frequency $f_{\text {pwm }}$ is set to $1 \mathrm{kHz}$ and the modulation index and dc voltage are 0.9 and 150 volts respectively. The first harmonic distortion is located at $2 f_{p w m}$ (unipolar PWM per H-bridge)

\section{Problem And Motivation}

To operate a CHB converter the use of independents dc power supplies for each H-bridge is mandatory. This fact permits to operate the $\mathrm{CHB}$ converter in a modular way allowing to connect each H-bridge to different nature dc sources. In this way, it is possible to consider the integration of renewable energy sources and energy storage systems (ESS) such as batteries or super-capacitors working together into the same power system. As an example, the photovoltaic application with independent solar arrays connected to each H-bridge is addressed in [17]-[24] and the ESS application in [25]-[27]. In all these cases, the different nature or operational points of dc sources result in an asymmetric power distribution between the H-bridges of the CHB converter. As an example, in [20] it is possible to observe this phenomenon where the CHB converter is considered for a PV application with different solar irradiation levels in each PV array. This fact leads to different operation points in the MPPT control for each power cell. Consequently, the dc voltage controller generates a unequal reference voltage for each power cell and the conventional PSPWM benefits are partially lost. The motivation of this work consists on the reduction of this negative effect eliminating the low-orders harmonic distortion located at unipolar carrier frequency multiples.

\section{Extended Adaptive Phase-Shifted PWM}

Considering a generic $M$-CHB converter and taking into account the previous frequency-domain analysis realized in [12], the output voltage of a $M$-cell CHB converter can be expressed using the Fourier expansion series as:

$$
\begin{aligned}
v(t)= & \sum_{m=1}^{M} v_{m}(t) \simeq \sum_{m=1}^{M}\left(V_{d c, m} D_{m}+\right. \\
& \left.+\sum_{n=1}^{\infty}\left[h_{m n} \cos \left(n \omega t+n \phi_{m}\right)\right]\right)
\end{aligned}
$$

In this general expression (1), $h_{m n}$ represents the $n$-th harmonic coefficient generated by the $m$-th cell in the power converter and it can be calculated using the following expression:

$$
h_{m n}=\frac{2 V_{d c, m}}{n \pi} \sin \left(n \pi D_{m}\right)
$$

In [12], the modification of the traditional PS-PWM was presented and validated in order to eliminate the low-order carrier harmonic in the global output voltage but only for a three-cell CHB converter. In [12], it is introduced an study in the frequency-domain of the global output voltage of $\mathrm{CHB}$ converter providing an exact solution to eliminate the first carrier harmonic content in the output voltage. As a summary for the three-cell case, the equation system to be solved is:

$$
\begin{aligned}
h_{11}+h_{12} \cos \left(\phi_{2}\right)+h_{13} \cos \left(\phi_{3}\right) & =0 \\
h_{12} \sin \left(\phi_{2}\right)+h_{13} \sin \left(\phi_{3}\right) & =0
\end{aligned}
$$

And the solution provided in [12] is the following:

$$
\begin{aligned}
\phi_{2} & =\arccos \left(\frac{-h_{11}^{2}-h_{12}^{2}+h_{13}^{2}}{2 h_{11} h_{12}}\right) \\
\phi_{3} & =\arccos \left(\frac{-h_{11}^{2}+h_{12}^{2}-h_{13}^{2}}{2 h_{11} h_{13}}\right) .
\end{aligned}
$$


However, if the number of power cells grows the equation system to eliminate the first carrier harmonic is more complex. As an example, if a four-cell CHB converter $(M=4)$ is considered, the equation system (considering $\phi_{1}=0$ ) is given by:

$$
\begin{aligned}
h_{11}+\sum_{m=2}^{4} h_{1 m} \cos \left(\phi_{m}\right) & =0 \\
\sum_{m=2}^{4} h_{1 m} \sin \left(\phi_{m}\right) & =0
\end{aligned}
$$

Even considering $\phi_{1}=0$, the number of variables in expression (5) is greater than the number of equations leading to a dependent equation system; in others words, for instance the solution set is infinite because it is possible to find a valid one for each value of $\phi_{4}$ considered.

On the other hand, if the second carrier harmonic is considered looking to a valid solution, the equation system described in (5) is:

$$
\begin{aligned}
h_{11}+\sum_{m=2}^{4} h_{1 m} \cos \left(\phi_{m}\right) & =0 \\
\sum_{m=2}^{4} h_{1 m} \sin \left(\phi_{m}\right) & =0 \\
h_{21}+\sum_{m=2}^{4} h_{2 m} \cos \left(2 \phi_{m}\right) & =0 \\
\sum_{m=2}^{4} h_{2 m} \sin \left(2 \phi_{m}\right) & =0
\end{aligned}
$$

In this case, is not possible to obtain the analytical solution and finding a numerical expression to solve it could be very difficult (or even not exist) because expression (6) is a nonlinear equation system. According to this, finding an analytical solution of (6) in real time is out of the scope of this paper. This discussion could be extended to $M$-cells and in the all cases the complexity will be higher and higher.

The aim of this paper is to present an extended variableangle PWM method for the $M$-cells CHB converter (with $M>3$ ) focusing only on the first-carrier harmonic elimination. It will consists on reducing the number of control variables in order to extrapolate the results presented in [12].

\section{A. Four-cell CHB power converter}

Taking into account the four-cell CHB converter, it seems trivial to find a possible solution if one angle is forced to be equal to $180^{\circ}$. In this case, if $\phi_{3}=180^{\circ}$, the equation system described in (5) is reduced to:

$$
\begin{aligned}
\left(h_{11}-h_{13}\right)+h_{12} \cos \left(\phi_{2}\right)+h_{14} \cos \left(\phi_{4}\right) & =0 \\
h_{12} \sin \left(\phi_{2}\right)+h_{14} \sin \left(\phi_{4}\right) & =0
\end{aligned}
$$

Defining $h^{\prime}=h_{11}-h_{13}$, and using (4) it is possible find a solution as:

$$
\begin{aligned}
\phi_{2} & =\arccos \left(\frac{-\left(h^{\prime}\right)^{2}-h_{12}^{2}+h_{14}^{2}}{2 h^{\prime} h_{12}}\right) \\
\phi_{3} & =\arccos \left(\frac{-\left(h^{\prime}\right)^{2}+h_{12}^{2}-h_{14}^{2}}{2 h^{\prime} h_{13}}\right) .
\end{aligned}
$$

\section{B. Five-cell CHB power converter}

If $M$ is higher than 4 , the previous method is not suitable for solving the problem. In order to solve the five-cell $\mathrm{CHB}$ case, a possibility is to create two different three-cell groups. The first carrier harmonic content produced by the first cell can be shared equally between the two groups. In this way, the equation system can be splitted off two different virtual three-cell systems as follows:

$$
\begin{aligned}
0.5 h_{11}+h_{12} \cos \left(\phi_{2}\right)+h_{14} \cos \left(\phi_{4}\right) & =0 \\
h_{12} \sin \left(\phi_{2}\right)+h_{14} \sin \left(\phi_{4}\right) & =0 \\
0.5 h_{11}+h_{13} \cos \left(\phi_{3}\right)+h_{15} \cos \left(\phi_{5}\right) & =0 \\
h_{13} \sin \left(\phi_{3}\right)+h_{15} \sin \left(\phi_{5}\right) & =0
\end{aligned}
$$

Applying again expression (4), it is possible to obtain a valid set of angles to eliminate the first carrier harmonic content.

\section{C. $C H B$ converter with large number of cells $(M>5)$}

The idea of splitting the CHB converter in several groups of power cells to simplify the problem is exportable when the number of cells is higher than 5. For instance, the sixcell case can be considered and in this case, there can be two independent three-cell groups. The equation system resulting for each group are:

$$
\begin{aligned}
h_{11}+h_{13} \cos \left(\phi_{3}\right)+h_{15} \cos \left(\phi_{5}\right) & =0 \\
h_{13} \sin \left(\phi_{3}\right)+h_{15} \sin \left(\phi_{5}\right) & =0 \\
h_{12}+h_{14} \cos \left(\phi_{4}\right)+h_{16} \cos \left(\phi_{6}\right) & =0 \\
h_{14} \sin \left(\phi_{4}\right)+h_{16} \sin \left(\phi_{6}\right) & =0
\end{aligned}
$$

Applying (4) and solving independently each group, it is possible to obtain a valid set of angles to eliminate the first carrier harmonic content for each group. However, to maintain the cascaded six-cell structure it is necessary to apply an offset angle between both groups. For simplicity, this offset angle between both groups is $60^{\circ}$ being determined by:

$$
\phi_{\text {offset }}=\frac{360^{\circ}}{M}
$$

Using this strategy, the first carrier-harmonic will be completely eliminated. Please, notice that the first harmonic content will be eliminated and independently of the offset angle value. This can be extended to CHB converters with $M$ large and multiple of three.

For $M$ large and non multiple of three, the problem can be faced on the same way splitting the power cells in different 


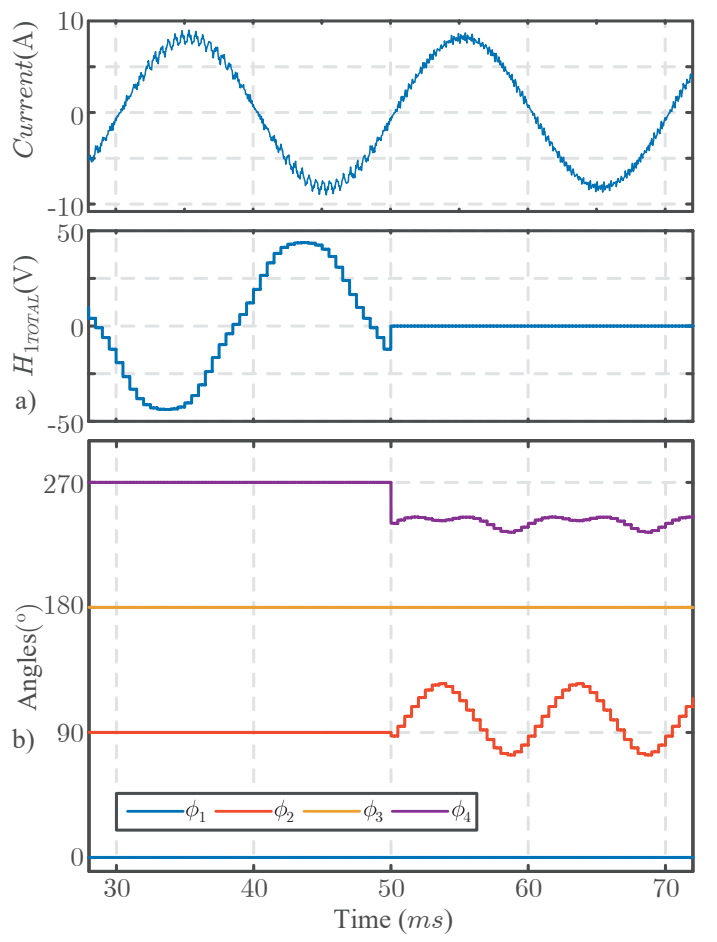

Fig. 3: a) Output current b) Harmonic content located at $2 f_{\text {pwm }}$ of the output voltage c) Phase displacement angles applied to the system under both modulation strategies for a four-cell CHB converter

groups formed by three, four or five cells and solving each group independently using previous expressions. The offset angle between groups can be calculated using (11) as well.

\section{Simulation Results}

In order to demonstrate the good performance of the proposed extended modulation technique, all cases mentioned above have been simulated using $f_{p w m}=1 \mathrm{kHz}$. In all cases, the scenario consists of operating a $M$-CHB converter under a hard asymmetric operational point. In order to compare the obtained results, it is necessary to use both the standard PSPWM modulation and the extended variable-angle technique. In the simulations, firstly is applied PS-PWM and the proposed method is applied after $t=50 \mathrm{~ms}$.

\section{A. Four-cell CHB power converter results}

In this case, the modulation indexes of each power cell are set to $0.80,0.75,0.95$ and 0.80 with dc voltages equals to $V_{d c, 1}=130 \mathrm{~V}, V_{d c, 2}=90 \mathrm{~V}, V_{d c, 3}=80 \mathrm{~V}$ and $V_{d c, 4}=100 \mathrm{~V}$, respectively. Under this hard asymmetric configuration, the resulting harmonic spectrum using the conventional PS-PWM presents a high distortion level located at the first carrier frequency $(2 \mathrm{kHz})$ as shown in Fig. 4, which is plotted using red bars. If the proposed variable-angle PS-PWM is applied, as shown in Fig. $3 \mathrm{c}$ the phase displacement angles are modified when $t>50 \mathrm{~ms}$ to eliminate the distortion located at $2 f_{\text {pwm }}$ as shown in Fig. 3b. Besides, the output current ripple is reduced

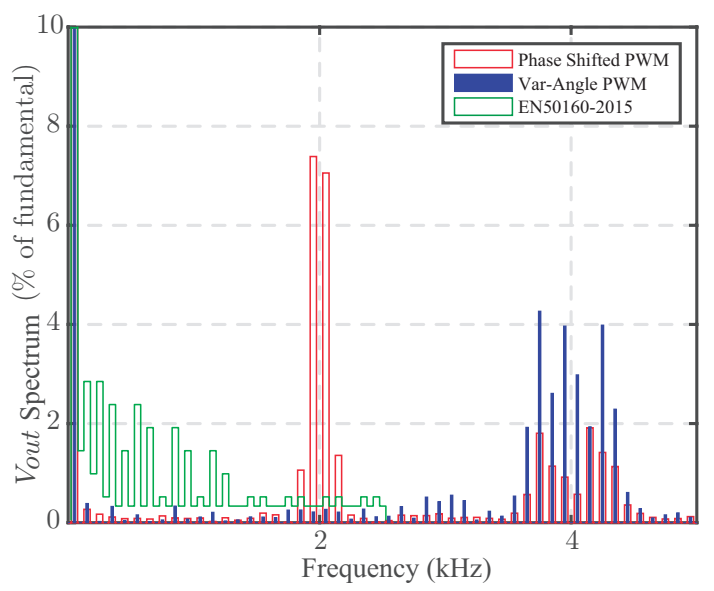

Fig. 4: EN50160-2015 grid regulation code (green line) and output voltage spectrum for a four-cell $\mathrm{CHB}$ converter using the traditional PS-PWM (red bars) and Variable-angle (solid blue bars) modulation techniques

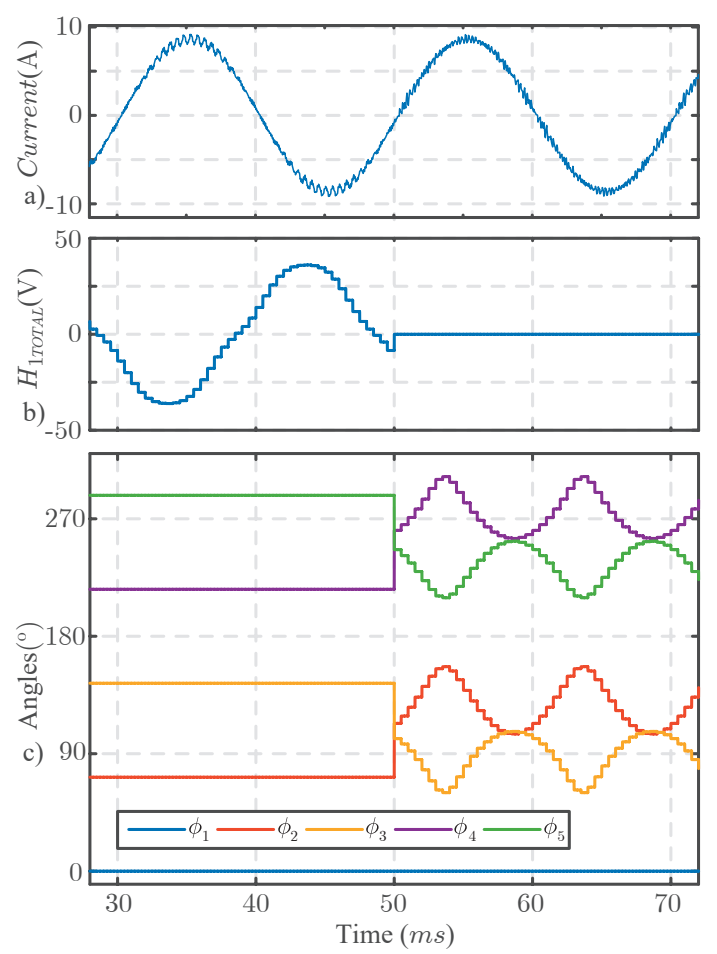

Fig. 5: a) Output current b) Harmonic content located at $2 f_{\text {pwm }}$ of the output voltage c) Phase displacement angles applied to the system under both modulation strategies for a five-cell CHB converter

as shown in Fig. 3c. The resulting spectrum is shown also in Fig. 4 using solid blue bars and can be observed that the first carrier harmonic content has been eliminated.

\section{B. Five-cell CHB power converter results}

In this case, the modulation indexes of each power cell are fixed to $0.75,0.80,0.85,0.90$ and 0.75 . The dc val- 


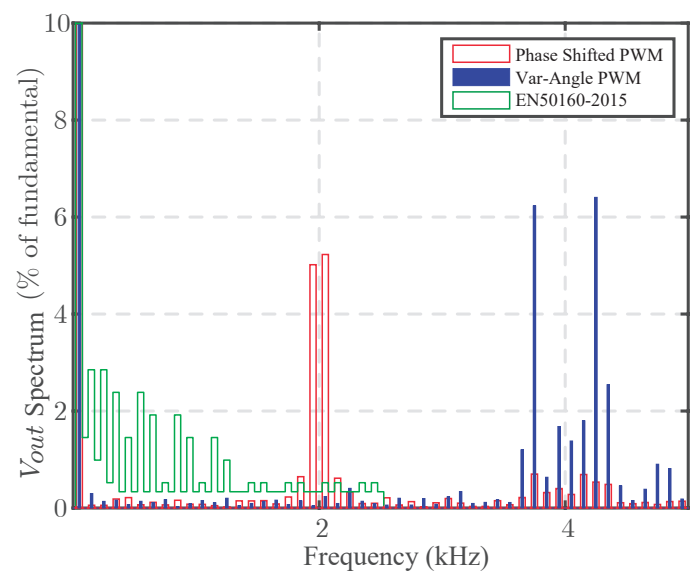

Fig. 6: EN50160-2015 grid regulation code (green line) and output voltage spectrum for a five-cell $\mathrm{CHB}$ converter using the traditional PS-PWM (red bars) and Variable-angle (solid blue bars) modulation techniques

ues are equals to $V_{d c, 1}=100 \mathrm{~V}, V_{d c, 2}=90 \mathrm{~V}, V_{d c, 3}=75 \mathrm{~V}$, $V_{d c, 4}=80 \mathrm{~V}$ and $V_{d c, 5}=85 \mathrm{~V}$ respectively. In this situation and using the traditional PS-PWM modulation, the resulting voltage spectrum has been plotted using red bars in Fig. 6. This harmonic spectrum presents a high harmonic content located at $2 \mathrm{kHz}$. According with the method described in previous sections, two virtual three-cell groups are created. The first group is formed by the cells 1,2 and 4 and the second group is composed by the cells 1,3 and 5 . From the instant $t=50 \mathrm{~ms}$, the variable-angle method is applied leading to the elimination of the first carrier harmonic content using the angles as plotted in Fig. 5b. The resulting voltage spectrum is represented also in Fig. 6 using solid blue bars.

\section{Six-cell $C H B$ power converter}

Finally, the six-cell CHB converter is taken into account. The modulation indexes used in the simulation scenario are the following: $0.80,0.65,0.85,0.80,0.90$ and 0.80 . The $\mathrm{dc}$ voltages used are $V_{d c, 1}=90 \mathrm{~V}, V_{d c, 2}=75 \mathrm{~V}, V_{d c, 3}=85 \mathrm{~V}$, $V_{d c, 4}=85 \mathrm{~V}, V_{d c, 5}=80 \mathrm{~V}$ and $V_{d c, 5}=48 \mathrm{~V}$ respectively. Under this situation and using the standard PS-PWM modulation, the resulting voltage spectrum has been represented in Fig. 8 using red bars. In accordance with the method deployed in the previous section, it is necessary to make two different groups of cells and solve them individually. The angle between groups is set to $60^{\circ}$ as it was calculated using 11 . The cells that form the first group are 1, 3 and 5 and the remaining cells form the second group. Following this structure and applying the proposed method from $t=50 \mathrm{~ms}$, the variable angles are shown in the Fig. $7 \mathrm{c}$ and the first harmonic content has been eliminated as can be seen in Fig. 7b. The resulting voltage spectrum has been plotted in Fig. 8 .

\section{CONCLUSIONS}

The cascaded H-bridge (CHB) converter, usually applied as motor drive or FACTS, is conventionally operated using
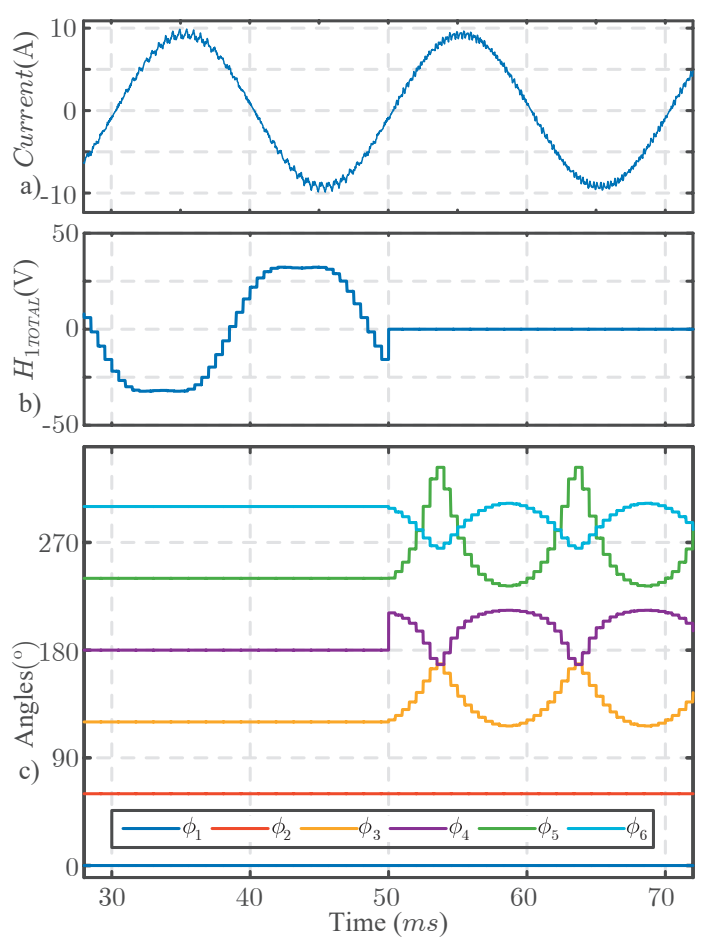

Fig. 7: a)Output current b) Harmonic content located at $2 f_{\text {pwm }}$ of output voltage c) Phase displacement angles applied to the system under both modulation strategies for a six-cell $\mathrm{CHB}$ converter

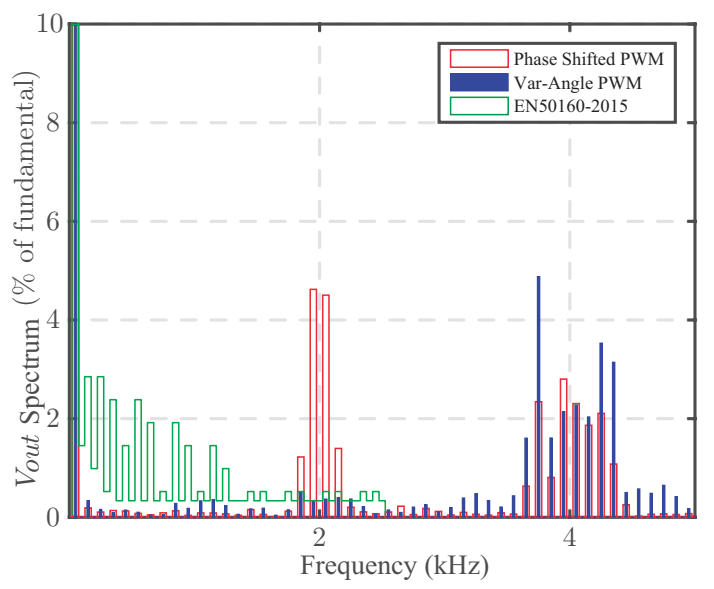

Fig. 8: EN50160-2015 grid regulation code (green line) and output voltage spectrum for a six-cell CHB converter using the traditional PS-PWM (red bars) and Variable-angle (solid blue bars) modulation techniques

a PS-PWM modulation method leading to advantages such as power equalization, equal power losses distribution and multiplicative effect of the switching frequency of the output waveforms. These advantages are partially lost if the dc sources are not working at the same operational point (different dc voltage value or different power). At a consequence, a high harmonic distortion is present at twice the carrier frequency 
degrading the converter performance. This is the case if the CHB converter is used for PV or energy storage systems applications.

In order to reduce this problem, an adaptive PS-PWM method where the phase displacement angles are not fixed can be used. However if the number of cells of the CHB is large, the required calculations to apply the method are not straightforward. In this paper, the required calculations to determine the angles are addressed and the results demonstrate that the harmonic distortion located at $2 f_{p w m}$ is eliminated. Simulation results demonstrate the good performance of the proposal under several scenarios.

\section{ACKNOWLEDGMENT}

The authors gratefully acknowledge the financial support provided by the Andalusian Government (project P11TIC-7070), the Spanish Ministry of Education and Science (project TEC2016-78430-R) Fondecyt (project 1151426), AC3E (CONICYT-Basal Project FB0008) and SERC Chile (CONICYT/FONDAP/15110019). This publication was also made possible by NPRP 9-310-2-134 from the Qatar National Research Fund (a member of Qatar Foundation). The statements made herein are solely the responsibility of the authors.

\section{REFERENCES}

[1] J. M. Carrasco, L. G. Franquelo, J. T. Bialasiewicz, E. Galvan, R Portillo, M. M. Prats, J. I. Leon and N. Moreno-Alfonso, "PowerElectronic Systems for the Grid Integration of Renewable Energy Sources: a Survey," IEEE Trans. Ind. Electron., vol. 53, no. 4, pp. 1002 1016, June 2006.

[2] L. G. Franquelo, J. I. Leon and S. Vazquez, "Power Electronics for Renewable Energy Systems, Transportation, and Industrial Applications - Chapter 2: Challenges of the Current Energy Scenario: The Power Electronics Contribution," First Edition, John Wiley \& Sons, 2014

[3] L. G. Franquelo, J. Rodriguez, J. I. Leon, S. Kouro, R. Portillo and M M. Prats, "The age of multilevel converters arrives," IEEE Trans. Ind. Electron. Magazine, vol. 2, no. 2, pp. 28-39, June 2008.

[4] J. Rodriguez, L. G. Franquelo, S. Kouro, J. I. Leon, R. Portillo, M. M. Prats and M. A. Perez, "Multilevel Converters: An Enabling Technology for High-Power Applications," Proceedings of the IEEE, vol. 97, no. 11, pp. 1786-1817, Nov. 2009.

[5] S. Kouro, M. Malinowski, K. Gopakumar, L. G. Franquelo, J. Pou, J. Rodriguez, B. Wu, M. A. Perez and J. I. Leon, "Recent Advances and Industrial Applications of Multilevel Converters," IEEE Trans. Ind. Electron., vol. 57, no. 8, pp. 2553-2580, Aug. 2010.

[6] S. Kouro, B. Wu, H. Abu-Rub and F. Blaabjerg, "Power Electronics for Renewable Energy Systems, Transportation, and Industrial Applications - Chapter 7: Photovoltaic energy conversion systems," First Edition, John Wiley \& Sons, 2014.

[7] J. I. Leon, S. Kouro, L. G. Franquelo, J. Rodriguez, and B. Wu, "The essential role and the continuous evolution of modulation techniques for voltage-source inverters in the past, present, and future power electronics," IEEE Trans. Ind. Electron., vol. 63, DOI 10.1109/TIE.2016.2519321, no. 5, pp. 2688-2701, May. 2016

[8] S. Daher, J. Schmid and F. L. M. Antunes, "Multilevel Inverter Topologies for Stand-Alone PV Systems," IEEE Trans. Ind. Electron., vol. 55 no. 7, pp. 2703-2712, July 2008.

[9] E. Romero-Cadaval, G. Spagnuolo, L. G. Franquelo, C. A. Ramos-Paja, T. Suntio and W. M. Xiao, "Grid-Connected Photovoltaic Generation Plants: Components and Operation," IEEE Ind. Electron. Magazine, vol. 7, no. 3, pp. 6-20, Sept. 2013.

[10] S. Kouro, J. I. Leon, D. Vinnikov and L. G. Franquelo, "Grid-Connected Photovoltaic Systems: An Overview of Recent Research and Emerging PV Converter Technology," IEEE Trans. Ind. Electron. Magazine, vol. 9, no. 1, pp. 47-61, March 2015
[11] M. Liserre, V. G. Monopoli, A. Dell'Aquilla, A. Pigazo and V. Moreno "Multilevel phase-shifting carrier pwm technique in case of non-equal dc-link voltages," in IECON 2006 - 32nd conference on IEEE Industrial Electronics, DOI 10.1109/IECON.2006.347669, pp 1639-1642, Noc 2006.

[12] A. Marquez, J. I. Leon, S. Vazquez, R. Portillo, L. G. Franquelo, E. Freire and S. Kouro "Variable-Angle Phase-Shifted PWM for Multilevel Three-Cell Cascaded H-bridge Converters," IEEE Trans. Ind. Electron., accepted for publication.

[13] J. I. Leon, S. Kouro, S.Vazquez, R. Portillo, L. G. Franquelo, J. M. Carrasco and J. Rodriguez, "Multidimensional Modulation Technique for Cascaded Multilevel Converters," IEEE Trans. Ind. Electron., vol. 58, no. 2, pp. 412-420, Feb. 2011

[14] A. Rathore and A. Edpuganti, "Fundamental Switching Frequency Optimal Pulse Width Modulation of Medium Voltage Cascaded SevenLevel Inverter," IEEE Trans. Industry Applicat., in press.

[15] C. Govindaraju and K. Baskaran, "Efficient Sequential Switching Hybrid-Modulation Techniques for Cascaded Multilevel Inverters," IEEE Trans. Power Electron., vol. 26, no. 6, pp. 1639-1648, June 2011.

[16] Younghoon Cho, T. LaBella, Jih-Sheng Lai and M. K. Senesky, "A Carrier-Based Neutral Voltage Modulation Strategy for Multilevel Cascaded Inverters Under Unbalanced DC Sources," IEEE Trans. Ind. Electron., vol. 61, no. 2, pp. 625-636, Feb. 2014.

[17] S. Kouro, B. Wu, A. Moya, E. Villanueva, P. Correa and J. Rodriguez, "Control of a cascaded H-bridge multilevel converter for grid connection of photovoltaic systems," in IEEE 35th Annual Conference of the Industrial Electronics Society (IECON 2009), pp. 3976-3982, Porto (Portugal), 3-5 Nov. 2009.

[18] E. Villanueva, P. Correa, J. Rodriguez and M. Pacas, "Control of a Single-Phase Cascaded H-Bridge Multilevel Inverter for Grid-Connected Photovoltaic Systems," IEEE Trans. Ind. Electron., vol. 56, no. 11, pp. 4399-4406, Nov. 2009.

[19] G. Buticchi, D. Barater, E. Lorenzani, C. Concari and G. Franceschini, "A Nine-Level Grid-Connected Converter Topology for Single-Phase Transformerless PV Systems," IEEE Trans. Ind. Electron., vol. 61, no. 8, pp. 3951-3960, Aug. 2014.

[20] A. Marquez, J. I. Leon, S. Vazquez and L. G. Franquelo, "Advanced control of a multilevel cascaded H-bridge converter for PV applications," in IEEE 40th Annual Conference of the Industrial Electronics Society (IECON 2014), pp. 4548-4553, Dallas (USA), Oct. 29 2014-Nov. 1 2014.

[21] S. Rivera, B. Wu, S. Kouro, Hong Wang and Donglai Zhang, "Cascaded H-bridge multilevel converter topology and three-phase balance control for large scale photovoltaic systems," in 3rd IEEE International Symposium on Power Electronics for Distributed Generation Systems (PEDG 2012), pp. 690-697, 25-28 June 2012.

[22] S. Rivera, S. Kouro, B. Wu, J. I. Leon, J. Rodriguez and L. G. Franquelo, "Cascaded H-bridge multilevel converter multistring topology for large scale photovoltaic systems," in 2011 IEEE International Symposium on Industrial Electronics (ISIE 2011), pp. 1837-1844, 27-30 June 2011.

[23] J. Chavarria, D. Biel, F. Guinjoan, C. Meza and J. J. Negroni, "EnergyBalance Control of PV Cascaded Multilevel Grid-Connected Inverters Under Level-Shifted and Phase-Shifted PWMs," IEEE Trans. Ind. Electron., vol. 60, no. 1, pp. 98-111, Jan. 2013.

[24] Bailu Xiao, Lijun Hang, Jun Mei, C. Riley, L. M. Tolbert and B. Ozpineci, "Modular Cascaded H-Bridge Multilevel PV Inverter With Distributed MPPT for Grid-Connected Applications," IEEE Trans. Industry Applicat., vol. 51, no. 2, pp. 1722-1731, March-April 2015.

[25] Liming Liu, Hui Li, Zhichao Wu and Yan Zhou, "A Cascaded Photovoltaic System Integrating Segmented Energy Storages With SelfRegulating Power Allocation Control and Wide Range Reactive Power Compensation," IEEE Trans. Power Electron., vol. 26, no. 12, pp. 35453559, Dec. 2011.

[26] P. Barrade, S. Delalay and A. Rufer, "Direct Connection of Supercapacitors to Photovoltaic Panels With On-Off Maximum Power Point Tracking," IEEE Trans. Sustainable Energy, vol. 3, no. 2, pp. 283-294, April 2012.

[27] M. Hamzeh, A. Ghazanfari, H. Mokhtari and H. Karimi, "Integrating hybrid power source into an islanded MV microgrid using CHB multilevel inverter under unbalanced and nonlinear load conditions," in IEEE 2014. 